\title{
Mining research and development - tactical versus strategic
}

\author{
P.A. Lilly Office of Research and Development, Curtin University, Australia
}

\section{Abstract}

While engaging in Research and Development (R\&D) is not of itself sufficient to guarantee the long term success of a mining company, those companies that do not invest strategically in $R \& D$ are unlikely to survive very long simply because they will not be able to maximise the value of their shareholders' assets in a rapidly-changing world. And while R\&D might not be core business for a mining company, innovation most definitely should be, and there is a strong link between R\&D and innovation, particularly in a capital and technology intensive industry such as mining. The paper provides an overview of the difference between tactical and strategic research and development initiatives, and how both are of value to a mining business. It demonstrates value in the context of Baghai et al. (1998) innovation framework, providing examples of actual innovations, and seeks to provide guidance on some of the management aspects of such initiatives.

\section{The fundamentals of R\&D}

It may be useful at the outset to discuss the key terms being used in this paper.

"Research" refers to "painstaking and systematic enquiry or careful examination into a subject in order to discover facts or principles" (Bernard, 1989). De Souza (2010) notes that research is needed when problems do not have immediate solutions. In the case of scientific research, he summarises the generic steps in the process as: defining the problem; surveying the literature; establishing the hypothesis or hypotheses to be tested; testing the hypothesis or hypotheses; establishing a thesis; and publishing (or otherwise reporting) the results.

Research, therefore, refers to a rigorous process aimed at creating new knowledge, theories, processes, etc. And while there is a plethora of subsets (basic, fundamental, pure, applied, etc.), the writer prefers to differentiate only between academic research (primarily for the purpose of creating new knowledge in its own right) and industrial research (primarily for the purpose of sustaining a business), at least in the context of this paper.

When we refer to something as being "strategic", it is usually from a relatively long term perspective and, in the case of an organisation, involves a significant commitment that often reduces flexibility to change direction. Hargadon (2003) notes that "strategy" answers two questions: where to go and how to get there. Consequently, strategic research can be thought of as that research having long term impact in which significant resources are invested, and which is potentially game-changing for science, an industry or a company.

When we refer to something as being tactical, it is usually from a short term perspective. It is (relative to strategy) easier to implement and easier to reverse if we wish to change it. Tactical research, therefore, can be thought of as research that meets relatively short term objectives. It usually has short term impact and does not often require significant investment of resources. It is also more likely to be incremental in its impact, rather than game-changing.

It is important to note that tactical research (or thinking) is no less important than strategic research (or thinking). Many senior executives have developed exciting strategic plans only to fail in their implementation. Likewise, strategic research will, at some stage, require a series of important tactical research projects delivering to shorter-term outcomes. 
Research almost always involves significant risk in the sense that it consumes resources but, no matter how tightly scoped, the outcomes are uncertain until well into the process. This is why it may make sense to invest in more than one research pathway to solve a particular strategic or tactical challenge. Putting all your metaphorical eggs in one equally metaphorical research basket is not always a good idea.

The definition of the term "development" in the context of this paper is the application of research outputs to the solution of practical problems. Development, therefore, is aimed at taking the outputs of research (for example, a new understanding of how rock material behaves under a variety of stress paths) and translating them into useful outcomes (for example, a new in situ stress measurement technique). It is common also to hear the term "demonstration" used (that is, research, development and demonstration) as this is usually the next step in the process of taking new knowledge and turning it into something useful for someone's business (for example, a piece of equipment that makes it possible to commercially apply the new in situ stress measurement technique). Demonstration is usually part of, or immediately precedes, the commercialisation process.

Universities such as Curtin, publically-funded research organisations (PFRO's) such as CSIRO and some private research institutions such as Batelle have as their core business: research, development, demonstration and commercialisation (or at the very least, knowledge/technology transfer). The front end of this process is often conducted by such organisations either entirely in-house or, quite commonly, in collaboration with organisations that have complimentary research capabilities. This is particularly true of strategic research, where few organisations genuinely have world-class expertise in all the necessary disciplines.

In the writer's opinion, the tax-payers' money that is being invested in research in universities and PFRO's should be primarily focussed on strategic challenges. However, the latter part of the research, development and demonstration process often involves a broader engagement with commercial organisations (such as venture capital companies, the services and equipment sector, etc.) and often becomes more tactical the closer it gets to market.

Mining companies are in the core business of finding, extracting, processing (to a greater or lesser extent) and then selling mineral or energy commodities. Research and development is not their core business. However, a successful mining company will use R\&D (or at the very least the commercialised outcomes of $R \& D)$ to improve its competitive position. Such R\&D can be undertaken using in-house capability, or contracted to external R\&D providers with the requisite capability and track record, or managed using some combination of the two end members (for example, in a partnership that shares the risks and the benefits). The vast majority of research undertaken by mining companies tends to be tactical. However, some mining companies do engage in genuinely strategic, potentially game-changing research. This depends very much on corporate strategy, and the terms "being on the bleeding edge" versus "being a fast follower" are often bandied about in this regard.

It is the writer's opinion that, while engaging in R\&D isn't of itself sufficient to guarantee the long term success of a mining company, those companies that do not invest strategically in R\&D are unlikely to survive very long simply because they will not be able to maximise the value of their shareholders' assets in a rapidly-changing world.

\section{A framework for thinking about innovation}

While R\&D might not be core business for a mining company, innovation most definitely should be, and there is a strong link between R\&D and innovation, particularly in a capital and technology intensive industry such as mining.

A typical definition of the word "innovate" is "to bring in something new" (Bernard, 1989). It refers to the improvement of old or creation of new products, technologies, ideas, etc. In the context of this paper, therefore, innovation involves taking new knowledge and transforming it into a tangible benefit or positive impact for a business. However, Hargadon (2003) also shows that many innovations are a recombination of 
"old" people, objects and ideas in new ways, a concept he refers to as "recombinant innovation" and, in a world of scarce human and financial resources, there is much to be said for this approach.

In the mining sector, innovation results in such impacts as reduced environmental footprint, increased productivity, reduced time to completion, minimised incidence of worker injury, increased net present value, reduced cost (capital or operating), to name a few.

Like R\&D, innovation usually involves risk because it requires a change from the status quo. Hargadon (2003) notes that the choice facing company executives is often a trade-off between better utilising existing technologies in order to survive today (a tactical approach) versus developing revolutionary new technologies to be strongly competitive tomorrow (a strategic approach). He refers to this as "exploitation" versus "exploration". The work of Christensen and Raynor (2003) has further shown that, when innovations are incremental (usually tactical), the larger established businesses in a sector tend to reinforce their dominance. Such businesses tend to be relatively conservative and inefficient in exploiting breakthrough or disruptive (often strategic) innovation.

Of course, there are exceptions to this generalisation but, in the writer's experience, not many. In the mining industry, often the capital intensity of the sector means that legacy systems and approaches cannot readily be changed. Tactical or incremental R\&D predominates. However, where new projects are developed, this is often a trigger for the entry of fresh thinking and technology by new or expanding companies with a different appetite for risk. The mineral exploration sub-sector, which is dominated by juniors, is replete with examples of this.

Baghai et al. (1998) have developed a widely-used framework of "horizons" in which to consider innovation for a business.

\section{1 Horizon 1}

Horizon 1 refers to innovation through incremental improvement within the existing components of the business. The authors give examples that include improving quality, extending an idea or perhaps looking at ways of incrementally reducing cost of production.

Horizon 1 innovation is therefore generally tactical in nature as it is relatively easy to implement, relatively easy to reverse if it needs to be changed, and requires relatively little investment in corporate resources.

The R\&D that is aimed at Horizon 1 innovation is generally tactical in nature. That is, very important to the short-term sustainability of the business but, if not supplemented with more strategic activity, unlikely to bring success to the business in the longer term.

An example of R\&D that led to this type of innovation was the conception, development and evolution of the Blastability Index (Lilly, 1986, 1992; Widzyk-Capehart and Lilly, 2001), briefly outlined here.

In the early 1980s, when the writer was employed in the Pilbara (Paraburdoo and Tom Price) as a senior mining engineer, it became clear that the pattern of rotating new, usually very young engineers through the drill-and-blast function for relatively short periods of time, usually less than 12 months, was leading to a great deal of repeated trial-and-error and inefficiency in a critical part of the production cycle; the fragmentation of rock. One of the biggest issues that new drill-and-blast engineers had to come to terms with was the highly variable nature of the rock mass. The writer therefore sought to develop a simple rock mass classification system that provided a rapid assessment, based on readily available input, of the propensity of a rock mass to fragment during blasting and which, for a given set of operating parameters (explosive type, bench height and hole diameter), was linearly related to energy factor. The resultant Blastability Index became routinely used in short-term planning. It also became used subsequently by the writer and others (e.g. Cunningham, 1987) in fragmentation modelling.

In summary, this was a tactical piece of $R \& D$ that led to an innovation that provided (incremental) improvement in blasting efficiency at the mines. 


\section{2 Horizon 2}

Horizon 2 refers to a more substantial innovation, the examples given by Baghai et al. (1998) being a new product idea or looking at selling an existing product to a completely new group of people.

In the context of this paper, therefore, Horizon 2 innovation is strategic in nature as it is likely to involve a much more significant commitment, is likely to be much more difficult to reverse, and if successful, could have a long term sustaining impact on the company.

The R\&D that is aimed at Horizon 2 innovation is also strategic in nature. It is looking beyond the next short-term planning or reporting period, and seeking to expand or enhance the business in new ways.

An example of the R\&D that led to a Horizon 2 innovation was that spun off from the Western Australian Telecommunications Research Institute at Curtin University in 2006 into a company called Sensear (Sensear, 2011). The technology, which is built into earmuffs, isolates and enhances speech while suppressing harmful background noise so that users can hear speech and stay protected in high noise environments. The current generation of development being undertaken jointly by Sensear and Curtin is focussed on a platform for noise measurements both in the ear and in the environment, with built in location measurements using an advanced GPS.

By way of another example, exploration for orebodies in a greenfields terrane is at the very least a Horizon 2 activity for a mining company and may lead to a Horizon 3 transformation.

\section{3 Horizon 3}

Baghai et al. (1998) refer to Horizon 3 innovation as disruptive, where people come up with ideas and technologies or ways of doing things that are so powerful that they entirely change the rules and shift the game. This too is highly strategic in nature; it is at the "game changing" end of the spectrum and is likely to completely transform a company's business. In the writer's view, it is very rare for Horizon 3 innovation to occur in mining companies. It is far more likely that this comes out of R\&D organisations or, indeed, other sectors.

A good example is the R\&D that led to a Horizon 3 innovation we now all know as the Wireless LAN, which came out of CSIRO's pioneering work in radioastronomy. "CSIRO's invention was granted a US patent in 1996... The technology was first embodied in an industry standard in 1999 (called IEEE 802.11a) and later in other standards (IEEE 802.11g and IEEE 802.11 draft n). As well as computers, it is now used to connect wirelessly many electrical and electronic devices including printers, game consoles, TV sets and phones. Forecasters predict that there are likely to be more than a billion devices sold worldwide over the next several years using the technology ... (CSIRO, 2011)." The impact of this work has been profound and gamechanging across all industry sectors, not just mining, and it has completely transformed the way we communicate.

\section{Thoughts on the management of tactical and strategic initiatives}

While many engineers and managers either intuitively understand or explicitly know of these concepts, few understand how best to manage these different horizons of R\&D and innovation. There is a strong tendency to manage Horizon 2 and 3 thinking and activity (including the associated R\&D) in the same way as that in Horizon 1. However, this is invariably a mistake.

Moore (2007), for example, recommends that Horizon 2 activities are, in a sense, sheltered from Horizon 1 activities and their management. He notes that Horizon 1 management processes, KPIs, goals, etc., are all aligned to sustaining and profitably underwriting existing, established operations and these get a lot of attention and resources. Horizon 3 activities, on the other hand, are highly visionary and exciting, and therefore supported too. However, Moore (2007) believes that Horizon 2 activities, unless there is some separation or sheltering, are likely to fail, as they need time to be successful and become established as valuable activities in their own right. 
That is not to say Horizon 2 research and development or related initiatives should not be well managed. "A Horizon 2 effort must be organized in such a way that its core functions are insulated and isolated until it can produce material revenues... During this ... phase, such projects require customised processes, metrics, and performance targets. They also require experienced entrepreneurial leaders who can navigate both the uncharted waters of emerging markets and the highly charted channels for getting things done inside the corporation. Finally, the (responsible senior executive) should call out Horizon 2 ventures specifically to give them (high-level) visibility. At regular intervals, their progress should be measured and communicated not in terms of revenues or.... market share but in terms of niche metrics ... Do this, and over time you will find you have effectively managed for the long term. The key, it turns out, is to focus intensely on the Horizon 2 challenge. Only then will your Horizon 3 investments live to support you in Horizon 1" (Moore, 2007).

In other words, if you don't manage your Horizon 2 activities properly, none of your Horizon 3 activities will make it through to Horizon 1.

\section{Conclusions}

R\&D is critical to innovation and therefore sustainability in a technologically-complex industry such as mining. Understanding how R\&D can add value to a company's business and that the management of such R\&D initiatives needs to be managed with some care, is a necessary part of a technical professional's arsenal. It is hoped that this paper, in some small way, helps stimulate interest in R\&D, innovation and its management within mining professionals.

As Steve Jobs (quoted in Fortune, 9 November 1998) said, "Innovation has nothing to do with how many $R \& D$ dollars you have. When Apple came up with the Mac, IBM was spending at least 100 times more on $R \& D$. It's not about money. It's about the people you have, how you're led, and how much you get it".

\section{Acknow l edgements}

The writer wishes to thank Mary Anne Lilly and Tim Walton for reviewing and commenting on the manuscript.

\section{References}

Baghai, M., Coley, S. and White, D. (1998) The Alchemy of Growth: Practical Insights for Building the Enduring Enterprise. Bernard, J.R.L. (ed) (1989) The pocket Macquarie dictionary, The Jacaranda Press, 1209 p.

Christensen, C.M. and Raynor, M.E. (2003) The innovator's solution, Harvard Business School Publishing, 304 p.

CSIRO (05/09/2009) viewed 21/06/2011, http://www.csiro.au/science/wireless-LANs--ci_pageNo-1.html.

Cunningham, C. (1987) Fragmentation estimation and the Kuz-Ram model-four years on, Second International Symposium on Rock Frag by Blasting, W.L. Fourney and R.D. Dick (eds), Society for Experimental Mechanics: Bethel, Connecticut, pp. 475-487.

De Souza, P. (2010) Innovation in industrial research, CSIRO Publishing, 135 p.

Hargadon, A. (2003) How breakthroughs happen, Harvard Business School Publishing, 254 p.

Lilly, P.A. (1986) An empirical method of assessing rock mass blastability, Large Open Pit Mining Conference, AusIMM, Newman, pp. 89-92.

Lilly, P.A. (1992) The use of the Blastability Index in the design of blasts for open pit mines, Western Australian Conference on Mining Geomechanics, Kalgoorlie, pp. 421-426.

Moore, G.A. (2007) To Succeed in the Long Term, Focus on the Middle Term, Harvard Business Review, Reprint R0707F.

Sensear Pty Ltd (2011) viewed 21/06/2011, http://www.sensear.com/.

Widzyk-Capehart, E. and Lilly, P.A. (2001) A review of practical considerations for rock mass blastability and fragmentation assessment, Explo 2001, AusIMM, Pokolbin, November. 
